\title{
The Behaviour of U.S. Public Debt and Deficits during the Global Financial Crisis
}

Thanh Dat Nguyen

Department of Economics and Finance, La Trobe University

Sandy Suardi ${ }^{1}$

School of Accounting, Economics and Finance, University of Wollongong

Chew Lian Chua

Melbourne Institute of Applied Economics and Social Research

\section{Abstract}

= In this paper we test the sustainability of U.S. public debt for the period 1916-2012 by analysing how the primary surplus to GDP responds to changes in the debt to GDP ratio in a time-varying parameter model. Further, we determine the stationarity property of the debt-GDP ratio while accommodating possible breaks in the data caused by wars and economic crisis under both the null and alternative hypotheses of an endogenous unit root test. The results show that the U.S. public debt is sustainable until 2005 when the primary surplus to GDP reacts negatively to the debt-income ratio. This is further exacerbated during the global financial crisis when primary surpluses continue to fall with increased debt thus jeopardising the sustainability of fiscal policy. While the stationarity test shows that the U.S. fiscal debt-GDP ratio is sustainable, it fails to highlight the risk that its debt policy is becoming unsustainable in recent years.

Keywords: Time-varying parameter; fiscal debt; global financial crisis

J.E.L. Reference Numbers: H62, E62, C2

\section{Introduction}

Macroeconomists and policy-makers have traditionally been concerned with the issue of the sustainability of public debt in developing and emerging market countries. However, since the global financial crisis the attention has shifted to developed economies which suffer from rising debt-GDP ratios in the face of stagnant or contracting output, aging population and liabilities from financial sectors. Of significant interest in the debate on fiscal sustainability is the U.S. economy in which the problem of a ballooning public debt has attracted significant media attention in recent years. This paper seeks to address the question of sustainability of the U.S. fiscal debt using a novel approach. Specifically, we seek to answer the questions: Has U.S. fiscal policy become unsustainable in the light of the global financial crisis? And if so, when did it become unsustainable?

The literature on testing the sustainability of U.S. fiscal policy is extensive. Using long time series data spanning the period 1916 to 1995, Bohn (1998) shows that the condition for the sustainability of fiscal policy is supported by the data and that the level of primary surpluses responds positively to marginal changes in the debt-GDP ratio. Despite the U.S. having suffered from extended periods of primary deficits, Bohn (1998) shows that the U.S. fiscal policy has been historically sustainable. Bohn (2008) uses an even longer data set spanning more than two centuries (1792-2003) and finds substantial

\footnotetext{
${ }^{1}$ Corresponding author at: School of Accounting, Economics and Finance, University of Wollongong, NSW 2500, Australia. Tel.: +612 42215525, E-mail: ssuardi@uow.edu.au

This is the author manuscript accepted for publication and has undergone full peer review but has not been through the copyediting, typesetting, pagination and proofreading process, which may lead to differences between this version and the Version of Record. Please cite this article as doi: 10.1111/coep.12166
} 
evidence in favour of a sustainable fiscal policy. Be that as it may, there are studies to the contrary which question the sustainability of U.S. fiscal policy (for example, see Hamilton and Flavin, 1986).

In this paper, we examine this issue of fiscal sustainability using the model-based specification of Bohn $(1998,2008)$. Bohn's (1998) model is widely regarded as a robust test for the sustainability of public debt over a given time path. However, this model assumes that the relationship between the primary surplus to GDP ratio and the debt-GDP ratio is time-invariant. Bohn (2008) alludes to permitting the policy rule (or reaction function) for the primary surplus-GDP ratio to be time-varying. Fincke and Greiner (2010) use the penalised spline estimation method to estimate a time-varying reaction function and examine the debt policies of a few African and Latin American countries. Our approach differs from both Bohn $(1998,2008)$ and Fincke and Greiner (2010) in that we modify Bohn's (1998) original parametric specification by casting it in a state space framework to accommodate a possible timevarying relationship between the primary surplus-GDP ratio and the debt-GDP ratio. We do this because we take into account the fact that the reaction of the primary surplus to variations in debt need not be constant but may be time-varying. Our prediction of a time-varying reaction function is in fact well supported by the data. The time-varying parameter model is estimated on a longer sample of the U.S. data (1916-2012) to determine whether the condition for fiscal sustainability is satisfied in recent years amidst growing concern and debate over the U.S. (un)sustainable debt policies. Paniagua et al. (2015) also apply a time-varying parameter model to study the sustainability of peripheral Euro countries' fiscal policy. Their model allows the fiscal reaction function to follow an autoregressive process. In contrast, we estimate a random coefficient model in which the transition equation of the fiscal reaction coefficient follows a random walk process.

In addition, we provide prima facie evidence by applying an alternative test that analyses the stationarity property of the stock of debt as a proportion of GDP. The earlier literature focusing on evaluating the sustainability of a government's fiscal financial strategy utilised the government intertemporal budget constraint to derive sufficient conditions for sustainability. These conditions require certain restrictions on the data generating process of some key fiscal aggregates, such as the stock of debt as a ratio of GDP or the inclusive-of-interest deficit as a proportion of GDP, which can be validated using standard unit root tests. ${ }^{2}$ It is noteworthy, however, that Bohn (2007) does not view the the order of integration as an appropriate test of fiscal policy sustainability as this would point toward the conclusion that the debt series are integrated of any finite order, which implies that the no-Ponzi scheme restriction holds. Be that as it may, testing the order of integration of the debt-GDP and surplusGDP ratio variables is crucial for the purpose of valid inference when estimating Bohn's (2007) model of the fiscal reaction function which may be viewed as a cointegrating relationship if both variables are I(1) or standard regression if they are $\mathrm{I}(0)$.

Given that close to nine decades of data are examined, the fiscal aggregate series are likely to be subjected to shifts in their mean and/or trend due to gradual or abrupt changes in fiscal policy resulting from, for example, war or economic crisis. Neglected structural breaks in the data are known to bias the commonly used integratibility tests toward favouring the unit root null (Perron, 1989). Even though a shifting mean or trend does not constitute evidence of sustainable fiscal policies, determining whether the form of of non-stationarity is deterministic or stochastic has pertinent economic policy implications.

\footnotetext{
${ }^{2}$ The bulk of the literature was initiated by the pioneering work of Hamilton and Flavin (1986) and further improved upon by Trehan and Walsh (1988, 1991), Buiter and Patel (1992), and Wickens and Uctum (1993), amongst others.
} 
Evidence of unsustainable fiscal policies due to the presence of stochastic trends in the data suggests permanent effects of shocks on the future values of fiscal aggregates and, in effect, eventual insolvency of the government. In contrast, evidence of unsustainability arising from deterministic components, such as a shifting mean or a changing trend, may imply transitory policy regime changes, so that the danger of insolvency can be remedied through appropriate fiscal reform.

Unit root tests that accommodate structural breaks, which have been employed to test fiscal sustainability are limited to the Zivot and Andrews (1992) test. ${ }^{3}$ This test assumes the null hypothesis of a unit root against the alternative of stationarity around a segmented deterministic trend or/and a shift in mean of unknown timing. One problem of employing such a test is that in the presence of structural break(s) in the unit-root process, the ZA test statistic suffers from size distortion that could lead to the erroneous conclusion that a time series is trend stationary when in fact it is nonstationary with breaks (Nunes et al., 1997; Lee and Strazicich, 2001). To mitigate this problem, we employ the two-break Lagrange Multiplier (LM) unit-root test developed by Lee and Strazicich (2003). Because the Lee and Strazicich (2003) test allows for breaks under both the null of a unit root and the alternative hypothesis of a stationary process, their test is robust to the presence of breaks under the unit-root null hypothesis (Lee and Strazicich, 2001). Camamero et al. (2015) employ a series of unit root tests that account for multiple structural breaks in both the null and alternative hypotheses at the pre-testing stage for the revenues, expenditures and debt of a group of 17 Organization for Economic Coperation and Development (OECD) countries. To our knowledge, their work is the only study on fiscal sustainability that determined whether fiscal debts in OECD countries are stationary in the presence of three structural breaks.

Our main findings are different from the previous literature. There is overwhelming evidence to suggest that the relationship between the primary surplus-GDP ratio and the debt-GDP ratio is timevarying. A plot of the coefficient governing their relationship suggests that the U.S. fiscal policy reacts aggressively to changes in the debt-GDP ratio during 1916-1940. From 1950 to 1995, we find evidence that the U.S. fiscal policy became less aggressive in reducing debt. Between 1995 to 2000, the positive response of the primary surplus-GDP ratio to the debt-GDP ratio increased sharply, suggesting that there was a dramatic corrective action in reducing the rising debt-income ratio. However, while the primary surplus-GDP ratio has continued to respond to the debt-GDP ratio positively since 2000, the effect of debt on primary surpluses has been decreasing at a rapid rate over that same period. By 2005 the effect of debt on primary surplus is negative, suggesting that fiscal policy in the U.S. has become unsustainable. This period is characterised by a significant decrease in the importance of debt reduction and coincides with the subprime and global financial crises when the financial sector passed huge liabilities to the government. On the other hand, the Lee and Strazicich (2003) test of stationarity suggests that the U.S. fiscal debt as a proportion of GDP follows a stationary process with two detected structural breaks in 1948 and 1966. Although this evidence points to a sustainable U.S. fiscal policy, which is consistent with the finding based on the constant fiscal reaction function, it fails to highlight the risk of U.S public debt policy becoming unsustainable in recent years.

The paper is organised as follows. Section 2 provides a survey of the literature, both theoretical and empirical test considerations and past empirical findings. Section 3 presents the data and tests of

\footnotetext{
${ }^{3}$ Papadopoulos and Sidiropoulos (1999) and Jha and Sharma (2004) are examples of using the Zivot and Andrews (1992) test to determine the stationarity property of debt and deficit in the presence of an endogenously determined break.
} 
fiscal sustainability. Section 4 discusses the empirical findings and results of some robustness tests. Section 5 concludes the paper.

\section{Literature Survey}

\subsection{Theoretical framework}

We start with the intertemporal budget (IBC) constraint following Walsh (2003) and Bohn (2008). The nominal government intertemporal budget constraint is given by:

$$
G_{t}+i_{t} B_{t-1}=T_{t}+\left(B_{t}-B_{t-1}\right)
$$

where $G_{t}$ is the government expenditure excluding interest payment, $B_{t}$ is the nominal government debt in period $t, i_{t-1} B_{t-1}$ is the interest payment on the outstanding debt from the previous period and $T_{t}$ is the tax revenue. The IBC can be expressed in terms of variables that are in proportion of GDP:

$$
\frac{G_{t}}{Y_{t}}+\frac{i_{t} B_{t-1}}{Y_{t-1}} \frac{Y_{t-1}}{Y_{t}}=\frac{T_{t}}{Y_{t}}+\frac{B_{t}}{Y_{t}}-\frac{B_{t-1}}{Y_{t-1}} \frac{Y_{t-1}}{Y_{t}},
$$

where $Y_{t}$ is GDP. Let $\mu_{t}$ be the real output growth rate and $\pi_{t}$ the inflation rate, then $(2)$ can be written as

$$
b_{t}=g_{t}-\tau_{t}+\left(1+\theta_{t}\right) b_{t-1} \text {, }
$$

where $b_{t}=\frac{B_{t}}{Y_{t}}, g_{t}=\frac{G_{t}}{Y_{t}}, \tau_{t}=\frac{T_{t}}{Y_{t}}$ and $\theta_{t}=\frac{1+i_{t}}{\left(1+\mu_{t}\right)\left(1+\pi_{t}\right)} \approx i_{t}-\pi_{t}-\mu_{t}$ is the real interest rate adjusted for real output growth rate. For simplicity we assume that the real interest rate adjusted for real output growth rate is positive and constant over time $\theta_{t-1}=\theta_{t}=\theta$. The future path of public debt for an arbitrary sequence of government spending and taxes is given by

$$
E_{t}\left[b_{t+n}\right]=\sum_{j=0}^{n}(1+\theta)^{n-j} E_{t}\left[g_{t+j}\right]-\sum_{j=0}^{n}(1+\theta)^{n-j} E_{t}\left[\tau_{t-j}\right]+(1+\theta)^{n} b_{t} .
$$

Making $b_{t}$ the subject yields

$$
b_{t}=\sum_{j=0}^{n}(1+\theta)^{-j} E_{t}\left[g_{t+j}\right]-\sum_{j=0}^{n}(1+\theta)^{-j} E_{t}\left[\tau_{t-j}\right]+(1+\theta)^{-n} E_{t}\left[b_{t+n}\right] .
$$

Define the primary surplus to GDP ratio as $s_{t}=\left(\tau_{t}-g_{t}\right)$, taking the limit of $(5)$ for $n \rightarrow \infty$ yield

$$
b_{t}=-\sum_{j=0}^{n}(1+\theta)^{-j} E_{t}\left[s_{t+j}\right]+\lim _{n \rightarrow \infty}(1+\theta)^{-n} E_{t}\left[b_{t+n}\right] .
$$

Fiscal solvency is satisfied provided that the second term in (6) is zero,

$$
\lim _{n \rightarrow \infty}(1+\theta)^{-n} E_{t}\left[b_{t+n}\right]=0 .
$$

This transversality condition is interpreted as the government does not accommodate Ponzi games, that 
is by continuously relying on the issue of new debt to pay maturing old debts. This condition is also known as the bondholders' transversality condition since bondholders are willing to hold public debt provided that they are assured about the government's solvency, that is the ability to redeem the entire debt at a future date without printing money and/or reneging on the commitment. The empirical test for the sustainability of the government's IBC is usually based on the analysis of the past behaviour of the fiscal policy variables.

Equation (7) suggests that for the transversality condition to hold it will require the time-series property of debt/deficits as a ratio to GDP to be a stationary process. Equation (6) implies that a certain cointegration relationship between government revenue and expenditure is a necessary condition for the government intertemporal budget constraint to hold. Accordingly the sustainability of the fiscal debt can be tested empirically using standard unit root tests on stock of debts as a proportion of GDP or the deficit to GDP ratio with deficit including interest payment, or an analysis of cointegration between public expenditure and revenue.

\subsection{Empirical Tests of Fiscal Sustainability}

Empirical tests of fiscal sustainability can be classified into two classes within the family of linear time-series methodologies. ${ }^{4}$ The first class of tests focuses on the time series property of debt, that is if debt follows a stationary process it is believed that fiscal debt will mean-revert thus implicitly satisfying fiscal sustainability (Hamilton and Flavin, 1986; Wilcox, 1989; Trehan and Walsh, 1991; Uctum and Wickens, 2000). An extension of this test involves determining the cointegration relationship between government expenditures and revenues which has been employed by Haug (1991) and Smith and Zin (1991). The rationale of this test is that even if government expenditures follow a non-stationary process, as long as they share a common stochastic trend with government revenues, fiscal sustainability is achievable.

Following the development of unit root test (Zivot and Andrews, 1992) and cointegration test (Hansen, 1992; Gregory and Hansen, 1996) with structural breaks, the literature on empirical tests of fiscal sustainability has recognised that the practice of assessing the long run fiscal sustainability using conventional unit root tests and cointegration tests with neglected structural breaks can be misleading. Consequently, it is necessary to accommodate possible structural breaks when testing for the stationary property of debt, government expenditure and revenue series, and their long-run relationships which could be caused by economic events. Failure to account for possible structural breaks in the data when testing for a unit root or when testing for a cointegration relationship can lead to erroneous conclusions. Makrydakis et al. (1999), Papadoupolous and Sidirodopoulos (1999) and Jha and Sharma (2004) employ the Zivot and Andrews (1992) unit root test, while the latter two studies apply the Gregory and Hansen (1996) cointegration test. Martin (2000) and Berenguer-Rico and Carrion-I-Silvestre (2011) use a different approach to test for the expenditure-revenues cointegration relationship while allowing for structural breaks. Specifically, the former uses a Bayesian approach while the latter study develops a new test statistic that can be employed to test for I(2) cointegration and multiple cointegration

\footnotetext{
${ }^{4}$ More recent work by Chortareas, Kapetanios and Uctum (2008), Cipolinni, Fattouh and Mouratidis (2008), Ricciuti (2008) and Chen (2014) adopts nonlinear time-series methodologies. This stream of work focuses on possible asymmetry in the adjustment of the budget deficit arising from policy-makers who respond differently to a deviation of the deficit and/or surplus from its long-run trend. This issue is outside the scope of the paper, as we are primarily interested in testing the sustainability of U.S. public debt policy in the light of the global financial crisis.
} 
relationships. Camarero et al. (2015) study the relationship between debt level and fiscal sustainability for a group of 17 OECD countries using unit root test statistics that accommodate multiple breaks in both the unit root null and the stationary alternative hypotheses. They also use a testing framework based on I(2) stochastic processes to undertake several types of cointegration and multicointegration tests between revenues and expenditures, and to analyse the stock-flow relationship of deficit and debt. Their pre-test for the existence of possible discontinuities in the series relies on the Perron and Yabu (2009) test and the Carrion-I-Silvestre et al. (2009) tests.

There are studies which choose to divide the sample according to the identified regime change such as the period after a war or when a new government is elected. Examples of this approach include the work of Hakkio and Rush (1991) and Quintos (1995), who divide their total sample into sub-sample periods and they test for cointegration relationship between government expenditures and revenues in the sub-samples. Choosing the break date in an ad hoc manner, however, is not a popular approach given the recent development in econometric techniques of structural break identification.

One criticism of the unit root and cointegration tests based on the intertemporal budget constraint is that they are difficult to implement in a stochastic environment, especially when interest rates on government bonds are below the GDP growth rate (Bohn,1995). For fiscal policy to be sustainable, the intertemporal budget constraint must hold. When the economic growth rate exceeds the interest rate, the government can 'grow' out of debt given that primary surplus rises faster than public debt (at least on a balanced growth path). Another pitfall of the fiscal sustainability test based on estimating a transversality condition is that it is sensitive to the choice of discount rates and the result can be obscured by war-time spending and by cyclical fluctuations in GDP.

The second class of tests is developed by Bohn $(1998,2008)$. This test is borne out of the lack of robustness in inference derived from unit roots and cointegration techniques when analysing fiscal policy sustainability. Bohn (2007, p.1846) argues that "Rejections of sustainability based on such tests are invalid because the intertemporal budget constraint may well be satisfied even if the components of the budget are not cointegrated and even if neither debts, or deficits, revenues, or spending are difference stationary." Furthermore, to circumvent the problem of dependence on interest rates and fluctuations in income growth when testing for fiscal sustainability, Bohn uses the tax-smoothing theory suggested by Barro (1986), and proposes the following fiscal reaction function:

$$
s_{t}=\rho d_{t}+\alpha Z_{t}+\varepsilon_{t},
$$

where $s_{t}$ is the primary surplus-GDP ratio, $d_{t}$ is the public debt-GDP ratio and $Z_{t}$ is a set of other determinants of the primary surplus, and $\varepsilon_{t}$ is an error term. Test for fiscal sustainability based on equation (8) focuses on the parameter estimate $\rho$. A positive response (i.e. $\rho>0$ ) implies that the government is reducing non-interest outlays or increasing revenue to offset changes in debt, so that the fiscal debt is sustainable. This way of testing for fiscal sustainability does not make any assumptions about interest rates or economic growth rates. Our test of fiscal sustainability falls within this framework.

2.3 Empirical Results on U.S. Fiscal Sustainability

There is a vast literature that studies and critiques the sustainability of U.S. fiscal policy based on 
various methods of testing for fiscal sustainability. The evidence, however, is mixed. The early work of Hamilton and Flavin (1986) apply the Dickey-Fuller unit root test on both deficit and debt for the period 1962-1984. They find that both series are stationary thereby suggesting that there is fiscal sustainability over this period. They went on to estimate the following regression:

$$
b_{t}=a_{0}(1+\theta)^{t}+\sum_{j=0}^{n}(1+\theta)^{-j} E_{t}\left[s_{t+j}\right]
$$

and find that $a_{0}$ is not significantly different from zero. The implication of this result is that the U.S. borrowing constraint is satisfied over the period 1962-1984. The conclusion of fiscal sustainability established by Hamilton and Flavin (1986) is also supported by Trehan and Walsh (1991) for the period 1961-1984 and Uctums and Wickens (2000) for the period 1965-1994. Both Trehan and Walsh (1991) and Uctums and Wickens (2000) apply the Dickey-Fuller test and the Phillips-Perron test on fiscal deficit and debt but they allow for time-varying real interest rate. One apparent difference in the empirical test results lies with the work of Wilcox (1989), who shows that fiscal sustainability is attained only during the period 1960-1974. However, subsequent to that period the result of the unit root test on discounted debt fails to reject the nonstationary null hypothesis implying that fiscal policy is on an unsustainable path in the decade after 1974.

Within the class of test that examines the unit root and cointegration property by accounting for structural breaks, the empirical results are at best mixed. Hakkio and Rush (1991) find the cointegrating slope coefficient of government expenditure is significantly smaller than unity for the sample period 1950-1988, suggesting that revenues do not respond adequately to increases in expenditures to achieve fiscal sustainability. Be that as it may, there are cointegration tests with structural breaks that point to the evidence that the U.S. fiscal policy is sustainable (see Quintos, 1995; Martin, 2000; Cunado et al., 2004; Berenguer-Rico and Carrion-I-Silvestre, 2011).

In a separate study by Barro (1986), who tests for U.S. fiscal policy sustainability using a maximum likelihood estimation approach on a tax smoothing model for the period 1916-1986, he finds statistical evidence for sustainable fiscal policy in the U.S. and inteprets the high deficits of 1982-1985 as consistent with the earlier period even though they are generated in reponse to a substantial recession in that period. Kremers (1989) also estimates the tax smoothing model and finds that the budget deficit responds significantly to the interest payment/GNP ratio for the period 1920-1981, implying that fiscal policy is sustainable. Nevertheless, for the period 1982-1985, Kremers (1989) fail to find that the budget deficit responds significantly to both debt/GNP and interest payment/GNP ratios. Finally, Bohn (1998, 2008) estimates the fiscal reaction function in equation (8) and finds the U.S. fiscal primary surplus responds positively to changes in debt. He concludes that the U.S. fiscal policy is sustainable over both sample periods: $1916-1995$ and 1792-2003.

\section{Data and Empirical Methodology}

\subsection{U.S. Fiscal Data}

Figure 1 displays the U.S. public debt-GDP ratio and the primary surplus (non-interest payment 
surplus) to GDP ratio for the period 1916 to $2012 .^{5}$ The role of the two world wars which led to the build-up of debt is depicted by the two steep increases in debt in 1916-1919 and 1941-1946. The public debt also increased rapidly in the last financial crisis. The increasing trend of public debt was also observed during the Great Depression (1929-1939) and during the 1980s, which was attributed to the hot phase of the Cold War (Bohn, 1998). In four of these five events, the increase in public debt was associated with a fall in the surplus-income ratio.

There were periods following the two world wars and in the late 1990s when the public debt decreased. The fall in public debt coincided with positive primary surpluses. Nevertheless, in the period after World War II, the public debt decreased dramatically while the primary surplus was relatively constant at zero. This observed pattern can be explained by the budget identity:

$$
D_{t}=D_{t-1}+D E F_{t} \text {, }
$$

where $D_{t}$ is the nominal public debt and $D E F_{t}$ is the nominal deficit. It can be shown that the change in debt-GDP ratio can be attributed to the deficit-GDP ratio and a nominal growth term such that

$$
\Delta\left(\frac{D}{Y}\right)_{t}=\frac{D_{t}}{Y_{t}}-\frac{D_{t-1}}{Y_{t-1}}=\frac{D E F_{t}}{Y_{t}}-\frac{D_{t-1}}{Y_{t-1}} \frac{g_{t}}{1+g_{t}},
$$

where $Y_{t}$ is the nominal GDP and $g_{t}$ is the nominal GDP growth rate, for which it can be decomposed into real growth effect and inflation effect. Based on equation (10), the significant drop in public debt after 1946 can be attributed to a recovery of economic growth after the war and inflation during that period.

\subsection{The History of Federal Spending and Debt}

Federal spending and debt in the U.S. has undergone dramatic changes in the nine decades of the sample period. We briefly discuss some institutional factors that affect fiscal decisions and that give rise to budget surpluses and deficits. Following the enactment of the 1921 Budget Act which provided much of the framework for the budgeting system that is in place today though with amendments in subsequent years, there has been a progressive philosophical shift in spending between 1921 and 1974 which began under President Woodrow Wilson. According to the 2015 Staff Analysis produced by the Joint Economic Committee, federal spending as a percentage of the economy (including the Civil War) averaged about 2.8 percent from the nation's founding through to 1920 , but it has increased to an average of 17.3 percent since then till $2012 .{ }^{6}$ This change was partly attributed to the new budget process which gave the President a more prominent role in directing federal spending and the expansion of the President's control over budgetary information through the establishment of the Bureau of the Budget.

From 1921 to 1931, a period during which spending expansion began, Republican presidents

\footnotetext{
${ }^{5}$ The data for the period 1916-1995 are obtained from Bohn (1998) while data for 1996-2011 are obtained from http://www.econ.ucsb.edu/126bohn/data.html.

6 "An Economic History of Federal Spending and Debt: Economics Growth and Federal Budgeting Trends with Insights for the Future" 2015 Staff Analysis produced by the Joint Economic Committee Republicans. Accessed from URL: jec.senate.gov/republicans.
} 
headed the executive and the Republicans held an uninterrupted Senate and House majority. During the last year of the Hoover administration in 1932, the U.S. economy plunged from recession into depression. It was necessary at that time to increase federal spending sharply, from 1.6 percent of estimated GDP in 1916 pre-World War I to 6.8 percent of GDP. Outside of the Civil War and the First World War, the federal spend-rate had never been higher as a percentage of GDP.

From 1933 and 1946, Congress was controlled by the Democrats. Even though the Roosevelt Administration drove spending during the New Deal, Congress reasserted its authority over spending and approached federal budgeting in a more responsible manner by enacting the Legislative Reorganization Act of 1946 and The Employment Act of 1946. The Legislative Reorganization Act provided the joint committee on the Legislative Budget to meet and produce a legislative budget at the beginning of each congressional session. While the agreement on a budget often was not adhered to by Congress, and the process was later abandoned, it did mark an attempt to improve federal budgeting. The 1946 Employment Act provided a credible platform to examine the broad economic developments and advised Congress on the economic ramifications of policies being considered. Some of these policies include the 1964 Kennedy tax cut and the 1980s Reagan tax cuts.

Further reforms took place following the 1946 efforts. In 1950, the House and Senate Appropriations Committees resolved to produce a single Omnibus Appropriations Act for FY1951. However, this Act did not continue into the future and the House and Senate reverted to individual appropriations measures. By the 1960s, budgets from the executive branch were presented in various forms that were opaque and confusing to the public and policy-makers. The 1967 Report of the President's Commission on Budget Concepts recommended the adoption of a unified budget and set forth a framework of budget concepts that largely underpin the budget process today. A Joint Study Committee on Budget Control was established in 1972 for which the budget system was established and under which the federal government operates today.

By 1985, the federal government had run a deficit in every year since 1970. This trend received much attention and led to the 1985 Balanced Budget and Emergency Deficit Control Act with its subsequent modifications leading to the "Gramm-Rudman" law named after Senator Phil Gramm who was the driving force. From the law's inception through the 1990s, the law put pressure on federal budgeting by focusing on federal deficits and deficit targets. This law, which remained in place through the 1990s and the budget surpluses in FY1998-FY2001, has been regarded as a "spending brake", keeping federal spending at a level below what it otherwise would have been. The law, however, was not renewed after 2002. The brief period of federal surpluses in FY1998-FY2001 was attributed to restrained growth in federal spending and strong economic growth.

Subsequent to 2001, there is a new era of big government and renewed increase in total spending. In addition, the business cycle changes with the bursting of the dot-com bubble, the 9/11 terrorist attacks and military engagements further returned the federal budget to deficits. By 2008, the nation's economy slumped into a financial crisis and the Great Recession set up the stage for massive government spending expansion through bailouts, Keynesian stimulus spending and the massive healthcare program known as Obamacare.

It is not clear how one could model these institutional developments over the nine decades of data. A dummy variable approach may seem appropriate but practically cumbersome as various institutional changes would require the use of different dummies to capture their effects on surpluses. 
On the other hand, the use of a time-varying parameter (or random coefficient) approach, which permits the relationship between deficit and surplus to vary with time, could to some degree capture the influence of these institutional developments on fiscal decisions and hence budget outcomes.

\subsection{Bohn's Time-Varying Fiscal Reaction Function}

Referring to equation (8), we note that the relationship between primary surplus and debt is not permitted to be time-varying in Bohn's (1995) specification. Yet as observed in Figure 1, both surpluses and debt display a systematic relationship that tends to vary with time. For this reason, we relax the assumption of a time-invariant $\rho$ and permit it to be time-varying. Canzoneri et al. (2001) show that such a time-varying policy rule is sustainable provided that $\rho_{t}$ is always non-negative in all period $t$. This condition may be deemed too restrictive. Greiner and Finke (2015) stipulate that a sufficient condition for fiscal sustainability is for the reaction coefficient $\rho$ to be positive on average.

In equation (8) $Z_{t}$ comprises the level of temporary government spending, GVAR, and the business cycle indicator, YVAR, both of which are shown to affect the level of primary surpluses based on the tax smoothing model of Barro (1979). Accordingly, we estimate the model

$$
\begin{gathered}
s_{t}=\rho_{t-1} d_{t-1}+\alpha_{0}+\alpha_{G} G V A R_{t}+\alpha_{Y} Y V A R_{t}+\varepsilon_{t}, \varepsilon_{t} \sim N\left(0, \sigma_{\varepsilon}^{2}\right), \\
\rho_{t-1}=\rho_{t-2}+\eta_{t-1}, \eta_{t-1} \sim N\left(0, \sigma_{\eta}^{2}\right) .
\end{gathered}
$$

Following Greiner et al. (2007) and Fincke and Greiner (2010), we allow the lagged debt ratio $d_{t-1}$ instead of contemporaneous debt ratio $d_{t}$ to influence current surplus. This is a reasonable assumption given that interest payments on debt and repayment on debt occur at latter periods. ${ }^{7}$ Following Barro (1986), GVAR and YVAR are calculated as

$$
\begin{gathered}
\text { VVAR }_{t}=\left(g_{t}-g_{t}^{*}\right) / y_{t} \text { and } \\
Y V A R_{t}=\left(1-y_{t} / y_{t}^{*}\right)\left(g_{t}^{*} / y_{t}\right),
\end{gathered}
$$

where $g_{t}$ and $y_{t}$ are the government spending and income levels at time $t$, respectively. Here, $g_{t}^{*}$ and $y_{t}^{*}$ are their trend levels and they are computed using the Hodrick-Prescott filter.

Other than controlling for the level of temporary government spending and business cycle fluctuations, it is possible that different political ideologies have different beliefs about the role of govenment and its size. In fact, the political-economy model on the "partisan budget cycle theory" (PBCT) advanced by Hibbs (1977) predicts that fiscal deficits tend to be larger when liberals politicians (i.e. Democrats) are in control of the government and smaller when conservative politicians (i.e. Republicans) are in control. Mahdavi (2014) performs Bohn's test for fiscal sustainability of the American

\footnotetext{
${ }^{7}$ We also estimate the time-varying parameter model with the term $\rho_{t} d_{t}$ in place of $\rho_{t-1} d_{t-1}$. The results are qualitatively unchanged although there are only marginal variations in the estimates and standard errors. Moreover, we estimated the model with longer lags of $d_{t}$ such as $d_{t-2}$ and $d_{t-3}$. The results remained qualitatively unchanged. However, the goodness-of-fit of the model is the best for $d_{t-1}$.
} 
state governments and finds that the conventional wisdom that fiscal position tends to deteriorate under a Democrat-controlled government is only partially supported by the state level data. Given that the president takes on a more prominent role in directing federal spending and has significant control over budgetary information, we include a president dummy of 1 for Democrat and 0 for Liberal in equation (11) to test the prediction of the PBCT. However, the estimation results reveal that this coefficient is not statistically significant at all conventional levels of significance, and the log likelihood of the model specification is significantly lower with the inclusion of this dummy variable. Consequently, we report the results of the model specification without the inclusion of the president dummy. ${ }^{8}$

The estimation of the signal equation (11) and the state equation (12) involves the use of the Kalman filter. Note that the residual terms, $\varepsilon_{t}$ and $\eta_{t}$ are serially independent with contemporaneous variance structure $\Omega_{t}$. Consider the conditional distribution of the state variable $\rho_{t}$ given information available at time $s$. The conditional mean and variance of the conditional distribution are $\rho_{t \mid s}=E_{s}\left(\rho_{t}\right)$ and $P_{t \mid s}=E_{s}\left[\left(\rho_{t}-\rho_{t \mid s}\right)^{2}\right]$, respectively, where the subscript below the expectation operator denotes the expectations are taken using the conditional distribution for that period. Based on these definitions, the one-step ahead mean and variance can be obtained by setting $s=t-1$. Note also that $P_{t \mid t-1}$ is the mean square error (MSE) of $\rho_{t \mid t-1}$. The one-step ahead estimate of $s_{t}$ the signal variable is $s_{t \mid t-1}=E_{t-1}\left(s_{t}\right)=E\left(s_{t} \mid \rho_{t \mid t-1}\right)$. Accordingly, the one-step ahead prediction error is given by $\varepsilon_{t \mid t-1}=S_{t}-S_{t \mid t-1}$ and the prediction error variance is defined as $f_{t \mid t-1}=\operatorname{var}\left(\varepsilon_{t \mid t-1}\right)$.

The Kalman filter is a recursive algorithm for sequentially updating the one-step ahead estimate of the state mean and variance given new information. Details of the recursion and the updating process of the state variable and its associated covariance are provided in the Appendix. For our purposes, it is sufficient to note that given initial values for the state mean and variance-covariance matrix $\Omega_{t}$, and observations on $s_{t}$ and the regressors, the Kalman filter may be used to compute one-step ahead estimates of the state and the associated mean square error variance $\left(\rho_{t \mid t-1}, P_{t \mid t-1}\right)$, the contemporaneous or filtered state mean and variance $\left(\rho_{t}, P_{t}\right)$ and the one-step ahead prediction, prediction error, and prediction error variance $\left(s_{t \mid t-1}, \varepsilon_{t \mid t-1}, f_{t \mid t-1}\right)$.

For a given sequence of data up to time period $T$, we can utilise information at any time period up to $T$ to form expectations through the fixed-interval smoothing. The smoothing procedure, which is provided in the Appendix, yields smoothed estimates of the states $\hat{\rho}_{t}=\rho_{t \mid T}$ and the smoothed estimates of the state variances, $V_{t}=\operatorname{var}_{T}\left(\rho_{t}\right)$. The matrix $V_{t}$ may be interpreted as the MSE of the smoothed state estimate $\hat{\rho}_{t}$. Like the one-step ahead states and variances, we may use the smoothed values to form smoothed estimates of the signal variables $\hat{s}_{t}=E\left(s_{t} \mid \hat{\rho}_{t}\right)$ and the variance of the smoothed signal estimates $S_{t}=\operatorname{var}\left(\hat{s}_{t \mid T}\right)$. The smoothing procedure also yields smoothed residual estimates $\hat{\varepsilon}_{t}=\varepsilon_{t \mid T}$ and $\hat{\eta}_{t}=\eta_{t \mid T}$, and a corresponding smoothed disturbance variance matrix

\footnotetext{
${ }^{8}$ Results for the model specification that includes the president dummy are available from the authors upon request.
} 
$\hat{\Omega}_{t}=\operatorname{var}_{T}\left[\left(\begin{array}{l}\varepsilon_{t} \\ \eta_{t}\end{array}\right)\right]$.

Under the assumption that the $\varepsilon_{t}$ and $\eta_{t}$ are Gaussian, the estimates of the parameter set $\left(\sigma_{\varepsilon}^{2}, \sigma_{\eta}^{2}, \alpha_{0}, \alpha_{G}, \alpha_{Y}\right)$ are obtained by maximising the log-likelihood:

$$
\log L(\theta)=-\frac{n T}{2} \log 2 \pi-\frac{1}{2} \sum_{t}\left(\log f_{t \mid t-1}+\frac{\left(s_{t}-s_{t \mid t-1}\right)^{2}}{f_{t \mid t-1}}\right)
$$

in which the one-step ahead estimate prediction error $s_{t}-s_{t \mid t-1}$, and its prediction error variance, $f_{t \mid t-1}$ are evaluated from the Kalman filter. In evaluating the Kalman filter and smoother procedures we use diffuse priors for the initial one-step ahead predicted values for the state $\rho_{100}$ and the filtered variance, $P_{1 \mid 0}$.

Note that prior to the estimation of the time-varying Bohn's (1995) specification, we first test for the stationarity property of the surplus-GDP and debt-GDP ratios. If the two series are found to be I(1), then the model can be estimated in a cointegration framework. But in the case that they are $I(0)$, it is essential to model $Z$ to avoid omitted variables bias. We now discuss the test for order of integration which allows for structural breaks.

\subsection{Stationarity Test of Debt-GDP and Surplus-GDP ratios}

Standard unit root tests like the Augmented Dickey-Fuller tests are known to have low power in the face of neglected structural breaks (Perron, 1989; Rappoport and Reichlin, 1989). For this reason, it is essential to undertake unit root tests that incorporate breaks. Although the Zivot and Andrew (1992) and Lumsdaine and Papell (1997) tests allow for breaks in the alternative hypothesis, these test statistics suffer from size distortion when there are structural break(s) in the unit root process. They could lead to a erroneous conclusion that a time series is trend stationary when in fact it is nonstationary with breaks (Nunes et al., 1997; Lee and Strazicich, 2001). On the other hand, the Lee and Strazicich (2003) test allows for the possible presence of structural break(s) when testing for a unit root in both the null and alternative hypotheses. Accordingly, we perform the Lee and Strazicich (2003) test on the stock of debt. This test also endogenously determines the break dates and is sufficiently flexible in permitting either the level to shift or both the level and trend to shift. The endogenous determination of break(s) possesses at least two advantages. First, it avoids test results that, in the linear framework, are biased towards non-rejection (Perron, 1989). Second, since this procedure can, unlike the nonlinear tests, identify when structural breaks occur, it can provide valuable information about whether the break is associated with a particular event. There are other unit root tests that permit breaks in both the null and alternative hypotheses. A case in point is Carrion-i-Silvestre, Kim and Perron (2009). Their tests are capable of testing for a unit root in the presence of more than two structural breaks.

The Lee and Strazicich (2003) Lagrange Multiplier (LM) unit-root test assumes the following data generating process (DGP):

$$
y_{t}=Z_{t} \delta+e_{t}
$$




$$
e_{t}=\beta e_{t-1}+\varepsilon_{t}
$$

for $t=1, \ldots, T$ where $Z_{t}$ is a vector of exogenous variables and $\varepsilon_{t} \sim N\left(0, \sigma^{2}\right)$. In this case, $y_{t}=d_{t}$ and $s_{t}$. To accommodate for the possibility of breaks in both the intercept $(D)$ and trend $(D T)$, we define $Z_{t}=\left[1, t, D_{1 t}, D_{2 t}, D T_{1 t}, D T_{2 t}\right]$. Here, $D_{j t}=1$ for $t \geq T B_{j}+1, j=1,2$ and 0 otherwise. $T B_{j}$ is the time period when a break occurs. Using the LM principle, we estimate the regression

$$
\Delta y_{t}=\delta^{\prime} \Delta Z_{t}+\phi \tilde{S}_{t-1}+u_{t}
$$

where $\tilde{S}_{t}=y_{t}-\tilde{\psi}_{x}-Z_{t} \tilde{\delta}, t=2, \ldots, T$ and $\tilde{\delta}$ are coefficients in the regression of $\Delta y_{t}$ on $\Delta Z_{t}$, $\tilde{\psi}_{x}=y_{1}-Z_{1} \tilde{\delta}$ and $y_{1}$ and $Z_{1}$ are the first observations of $y_{t}$ and $Z_{t}$, respectively. Under the unit root null, the LM test statistic, $\tilde{\tau}$, is given by the t-statistic for $\phi=0$ from equation (15). The breakpoint $(T B)$ is determined by selecting the minimum t-statistic from all possible breakpoints given by $L M_{\tau}=\operatorname{Inf}_{\lambda} \tilde{\tau}(\lambda)$ where $\lambda=T B / T$. The search for the breakpoint is performed over the trimming region $(0.15 T, 0.85 T)$ where $T$ is the sample size. Critical values for the two-break case are obtained from Table 2 in Lee and Strazicich (2003), which depends on the value of $\lambda$.

An obvious limitation of the Lee and Strazicich (2003) LM test is that the trimming region of $15 \%$ would have prevented the detection of possible breaks associated with the global financial crisis given the annual frequency of the data and its sample period. Nevertheless, the test statistic is shown to exhibit good empirical size in the presence of breaks under the null hypothesis unlike the Lumsdaine and Papell (1997) test. Using the two-break min LM unit root test, rejection of the null hypothesis unambiguously implies trend stationary.

\section{Empirical Results}

\subsection{Bohn's Time-Varying Fiscal Reaction Function}

The results are summarised in Table 1 . All coefficient estimates are statistically significant at the $5 \%$ significance level. The coefficients of GVAR and YVAR are negative which is consistent with Bohn's (1995) and Barro's (1986) results. To ensure that $\sigma_{\varepsilon}^{2}$ and $\sigma_{\eta}^{2}$ are positive, we define $\sigma_{\varepsilon}^{2}=\exp \left(\theta_{\varepsilon}\right)$ and $\sigma_{\eta}^{2}=\exp \left(\theta_{\eta}\right)$. Given that $\hat{\theta}_{\varepsilon}=-9.3765$ and $\hat{\theta}_{\eta}=-7.2046$, this implies that $\hat{\sigma}_{\varepsilon}=0.0092$ and $\hat{\sigma}_{\eta}=0.0273$, respectively.

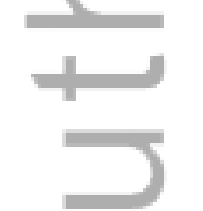

-Table1abouthere-

-Figure2abouthere-

Figure 2 plots the time-varying slope $\rho_{t-1}$ with the dashed lines signifying the 95 percent confidence intervals. The figure suggests there is significant time variation in the slope coefficient $\rho_{t-1}$. 
Looking at the point estimates of $\rho_{t-1}$ for Bohn's (1995) sample period (1916-1995), the results by and large concur with his findings that $\hat{\rho}_{t-1}>0$ except for 1942 when $\hat{\rho}_{t-1}<0$ (i.e. $\hat{\rho}_{1941}=-0.0298$ ). This is due to the effect of World War II in which we observe an exceptionally high level of government expenditure and output went below its trend. Even though the estimated debt reaction coefficient is positive, the time-varying plot $\hat{\rho}_{t-1}$ suggests interesting dynamics in the relationship between primary surplus- and debt-income ratios. Over the period 1916-1934, the average $\hat{\rho}_{t-1}$ is above .05 . The importance of debt reduction has declined during World War II but this changed after the war ended. However, for the period 1954-1995, $\hat{\rho}_{t-1}$ averages below .05 suggesting that the actions taken by the government to counteract the changes in debt have become less aggressive compared to the period prior to World War II.

Since 1995 there has been a dramatic increase in $\hat{\rho}_{t-1}$; it reaches its peak in 2000 at $\hat{\rho}_{1999}=0.1175$ before falling rapidly thereafter. The reduction in $\hat{\rho}_{t-1}$ to a negative territory implies that the US fiscal policy has become unsustainable after 2004. It is evident from the plot that there has been little emphasis on debt reduction during the period of the subprime and global financial crises (2007-2009). This is not surprising given the huge liabilities which the financial sector passed on to the government during that period. The value of $\hat{\rho}_{t-1}$ during the crises period fell to a level that is lower than that of World War II. It is clear from our time-varying parameter model that the data do indeed point to concerns over the U.S. unsustainable fiscal debt. More importantly, our results indicate that concerns with the sustainability of the fiscal debt should have been raised earlier, in or about 2005. Another important aspect of our finding is that we are able to show the time-varying pattern of fiscal sustainability which would otherwise be concealed using standard least squares regression. For the purpose of comparison, we run the regression (11) with $\rho_{t-1}=\rho$. The results reported in Table 2 show that $\hat{\rho}$ is 0.0259 and it is statistically significant at the $5 \%$ level, which implies that fiscal policy in the U.S. would have been deemed sustainable. The standard regression, however, fails to show the change in the dynamic of U.S. public debt as demonstrated by the time-varying parameter model.

-Table2abouthere-

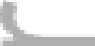

-Figure3abouthere-

Finally, to assess the adequacy of the time-varying parameter model in characterising the data, we plot in Figure 3 the primary suplus-GDP ratio together with the in-sample fit of the two competing models. It can be seen that the time-varying parameter model provides a superior characterisation of the primary surplus-income ratio to the time-invariant parameter model. This is most evident for the period subsequent to 1995 when the time-invariant parameter model fails to estimate the true primary surplus-income ratio while the time-varying parameter model provides more accurate estimates of the ratio. The root mean-squared errors of the two models ( $R M S E_{\text {Time-varying }}=0.007062$, $R M S E_{\text {Linear }}=0.021031$ ) further confirm the superior in-sample fit of the time-varying parameter model. 


\subsection{Stationarity Test of Debt-GDP and Surplus-GDP ratios}

It can be seen in Table 3(a) that the LM test statistic of -5.96 is smaller than the critical values for various $\lambda_{1}$ and $\lambda_{2}$ values at $5 \%$ and $10 \%$ significance levels. ${ }^{9}$ This implies that the test rejects the null of nonstationarity with two breaks in both level and trend at the $5 \%$ significance level. There is evidence to suggest that the U.S. fiscal debt is stationary with breaks. The two break dates are 1948 and 1966 with the former date coinciding with the massive fiscal spending in the economy after WWII. As for the results of surplus-GDP ratio in Table $3(\mathrm{~b})$, the LM test statistic of -7.43 also rejects the null of nonstationarity with two breaks in both level and trend at the $5 \%$ significance level, implying that surplus as a proportion of GDP is stationary with breaks.

Although the stationarity test result suggests prima facie evidence that the U.S. public debt policy is sustainable, it fails to highlight the risk of fiscal policy becoming unsustainable in the period leading up to the global financial crisis, which the time-varying model of fiscal reaction function demonstrates. Our results showcase a change in the behaviour of U.S. public debt and deficits in the periods around the global financial crisis, which warrants policy-makers to undertake precautionary measures such as increasing surpluses in response to debts to ensure that U.S. fiscal policy is sustainable in the future.

5 Conclusion - Table3abouthere -

The rise in public deficit and debt-GDP ratios amongst some industrialised economies during the global financial crisis has posed global concerns over fiscal sustainability. The U.S. is obviously not outside this trend; the U.S. recorded a fiscal debt equivalent to more than 100 percent of the country's GDP in 2012. How does the U.S. government react to such an increase in debt? Does fiscal policy follow a sustainable path? To answer these questions, this paper employs a time-varying parameter model based on Bohn's (1998) regression to examine the importance of debt reduction in the U.S. over the period 1916-2012. It also examines the stationarity property of the stock of debt to GDP ratio using a unit root test that is robust to structural breaks in both the null and alternative hypotheses.

We find evidence that the U.S. fiscal policy has been sustainable for the period 1916-1995 as documented by Bohn (1998). While there is evidence that the coefficient measuring the response of the primary surplus-income ratio to the debt-GDP ratio is time-varying, this coefficient has remained largely positive. However, we further show that, since 2005, the importance of debt reduction has declined with the primary budget surplus responding negatively to changes in the debt-income ratio. Concerns over a U.S. unsustainable fiscal policy are legitimate as the time-varying estimate plot shows that there is a steep declining trend in the reaction coefficient of the debt-income ratio in the negative territory, which violates the condition for fiscal sustainability. The recent subprime and global financial crises led partly to that accumulation of greater debt, as government took on huge liabilities from the financial

${ }^{9}$ Critical values for the two-break case are obtained from Table 2 Model C(II) $L M_{\tau}$ in Lee and Strazicich (2003). 
sector. Although the stationarity test result on the stock of debt-GDP ratio points to the public debt being sustainable, it fails to detect changes in the dynamic of public debt that could jeopardise the sustainability of U.S. fiscal policy.

Although we identify the decline in primary budget surplus to changes in debt-income ratio since 2005, it is worth noting that running a primary surplus on average is not necessary to prevent the debt from exploding. As long as interest rates are low, the government can exploit this low cost of borrowing and run primary deficits in most states of nature without the debt to GDP ratio increasing provided that the rate of GDP growth is greater than the rate of growth of debt.

$=$

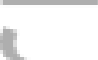

$\infty$
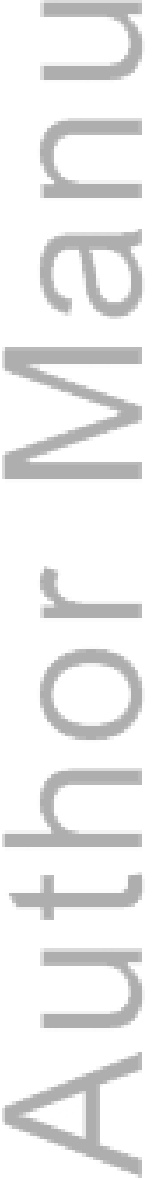

This article is protected by copyright. All rights reserved. 


\section{References}

[1] Barro, R.J. (1986), "U.S. deficits since World War I", Scandinavian Journal of Economics, $88,195-222$.

[2] Berenguer-Rico, V. and J.L. Carrio-I-Silvestre (2011), "Regime shifts in stock-flow I(2)-I(1) systems: the case of US fiscal sustainability", Journal of Applied Econometrics, 26, 298321.

= [3] Bohn, H. (1995), "The sustainability of budget deficits in a stochastic economy", Journal of Money, Credit and Banking, 27, 257-271.

[4] Bohn, H. (1998), "The behaviour of US public debt and deficits", Quarterly Journal of Economics, 113, 949-963.

[5] Bohn, H. (2007), "Are stationary and cointegration restrictions really necessary for intertemporal budget constraint?", Journal of Monetary Economics, 57, 1837-1847.

[6] Bohn, H. (2008), "The sustainability of Fiscal policy in the United States", in Sustainability of Public Debt, edited by Neck, R. and J. Strurm, MIT press, 15-49.

[7] Buiter, W.H. and U.R. Patel (1992), "Debt, deficits and inflation: an application to the public finances of India", Journal of Public Economics, 47, 171-205.

[8] Camarero, M., J.L. Carrion-I-Silvestre, and C. Tamarit (2015), "The relationship between debt level and fiscal sustainability in Organisation for Economic Cooperation and Development countries", Economic Inquiry, 53, 129-149.

[9] Canzoneri, M.B., R.E. Cumby, and B.T. Diba (2001), "Is the price level determined by the need for fiscal solvency?", American Economic Review, 91, 1221-1238.

[10] Carrion-I-Silvestre, J.L., D. Kim and P. Perron (2009), "GLS-based unit root tests with multiple structural breaks under both the null and the alternative hypotheses", Econometric Theory, 25, 1754-1792.

[11] Chen, S. (2014), "Testing for fiscal sustainability: New evidence from the G-7 and some European countries", Economic Modelling, 37, 1-15.

[12] Chortareas, G., G. Kapetanios, and M. Uctum (2008), "Nonlinear alternatives to unit root tests and public finances sustainability: Some evidence from Latin American and Caribbean countries", Oxford Bulletin of Economics and Statistics, 70, 645-663.

[13] Cipollini, A., B. Fattouh, and K. Mouratidis (2008), "Fiscal readjustments in the United States: A nonlinear time-series analysis", Economic Inquiry, 47, 34-54.

[14] Cunado, J., L.A. Gil-Alana, and F.P. Garcia (2004), "Is the US fiscal deficit sustainable? A fractionally integrated approach", Journal of Economics and Business, 56, 501-526.

[15] Fincke, B. and A. Greiner (2010), "Do governments in developing countries pursue sustainable debt policies? Empirical evidence for selected countries in Africa and Latin America", Journal of Development Studies, 46, 745-770.

[16] Fincke, B. and A. Greiner (2015), Public Debt, Sustainability and Economic Growth: Theory and Empirics, Springer, Heidelberg.

[17] Gregory, A.W. and B.E. Hansen (1996), "Residual based tests for cointegration in 
models with regime shifts", Journal of Econometrics, 70, 99-126.

[18] Hamilton, J. and M. Flavin (1986), "On the limitation of government borrowing: a framework of empirical testing", American Economic Review, 76, 808-819.

[19] Hansen, B.E. (1992), "Tests for parameter instability in regressions with I(1) processes", Journal of Business and Economic Statistics, 10, 321-335.

[20] Haug, A. (1995), "Has federal budget deficit policy changed in recent years?", Economic Inquiry, 33, 104-118.

[21] Hakkio, G. and M. Rush (1991), "Is the budget deficit 'too large'?", Economic Inquiry, 28, 429-445.

[22] Hibbs, D. (1977), "Political parties and macroeconomic policy", American Political Science Review, 71, 1467-1487.

[23] Jha, R. and A. Sharma (2004), "Structural breaks, unit roots and cointegration: A further test of the sustainability of the Indian fiscal deficit", Public Finance Review, 32, 196-219.

[24] Kremers, J. (1989), "U.S. federal indebtedness and the conduct of fiscal policy", Journal of Monetary Economics, 23, 219-238.

[25] Lee, J. and Strazicich, M. (2001), " Break point estimation and spurious rejections with endogenous unit root tests", Oxford Bulletin of Economics and Statistics, 63, 535-558.

[26] Lee, J. and M. Strazicich (2003), " Minimum Lagrange Multiplier unit root tests with two structural breaks", Review of Economics and Statistics, 81, 1082-1089.

[27] Lumsdaine, R.L. and D.H. Papell (1997), " Multiple trend breaks and the unit root hypothesis", Review of Economics and Statistics, 79, 212-218.

[28] Mahdavi, S. (2014), "Bohn's test of fiscal sustainability of the American state governments", Southern Economic Journal, 80, 1028-1054.

[29] Makrydakis, S., E. Tzavalis, and A. Balfoussias (1999), "Policy regime changes and the long-run sustainability of fiscal policy: an application to Greece", Economic Modelling, 16, 71-86.

[30] Martin, G.M. (2000), "US deficit sustainability: A new approach based on multiple endogenous breaks", Journal of Applied Econometrics, 15, 83-105.

[31] Nunes, L., P. Newbold, and C. Kuan (1997), "Testing for unit roots with breaks: Evidence on the Great crash and the unit root hypothesis reconsidered", Oxford Bulletin of Economics and Statistics, 59, 435-448.

[32] Paniagua, J., J. Sapena and C. Tamirit (2015), "Fiscal sustainability of peripheral EMU countries: continued vs. transitory fiscal commitment?" mimeo. Paper presented at XVIII Encuentro de Economia Aplicada. University of Alicante.

[33] Papadopoulos, A. and Sidiropoulos, M. (1999), "The sustainability of fiscal policies in the European Union", International Advances in Economic Research, 15, 289-307.

[34] Perron, P. (1989), "The great crash, the oil price shock and the unit root hypothesis", Econometrica, 57, 1361-1401.

[35] Perron, P. and T. Yabu (2009), "Testing for shifts in trend with an integrated or stationary noise component", Journal of Business and Economic Statistics, 27, 369-396.

[36] Quintos, C.E. (1995), "Sustainability of the deficit process with structural shifts", Journal of Business and Economic Statistics, 13, 409-417. 
[37] Rappoport, P. and Reichlin, L. (1989), " Segmented trends and nonstationary time series", Economic Journal, 99, 168-177.

[38] Ricciuti, R. (2008), "The quest for a fiscal rule: Italy, 1861-1998", Climometrica, Journal of Historical Economics and Econometric History, 2, 259-274.

[39] Smith, G. and S.E. Zin (1991), "Persistent deficits and the market value of government debt", Journal of Applied Econometrics, 6, 31-44.

[40] Trehan, B. and C.E. Walsh (1988), "Common trends, the government budget constraint, and revenue smoothing", Journal of Economic Dynamics and Control, 12, 425-444.

[41] Trehan, B. and C.E. Walsh (1991), "Testing intertemporal budget constraint: Theory and applications to U.S. federal budget and current account deficits", Journal of Money, Credit and Banking, 23, 206-223.

[42] Uctum, M. and M. Wickens (2000), "Debt and deficit ceilings, and sustainability of fiscal policies: an intertemporal analysis", Oxford Bulletin of Economics and Statistics, 62, 197222.

[43] Walsh, C.E. (2003), Monetary Theory and Policy, Cambridge, MA: MIT Press.

[44] Wickens, M.R. and M. Uctum (1993), "The sustainability of current account deficits: a test of the US intertemporal budget constraint", Journal of Economic Dynamics and Control, 17, 423-441.

[45] Wilcox, D. (1989), "The sustainability of government deficits: implications of the present value constraint", Journal of Money, Credit and Banking, 21, 291-306.

[46] Zivot, E. and D.W.K. Andrews (1992), " Further evidence on the great crash, the oil price shock and the unit root hypothesis", Journal of Business and Economic Statistics, 10, 251-270.

\section{Appendix}

Consider a linear state space model:

$$
\begin{aligned}
& y_{t}=x_{t} \beta_{t}+\varepsilon_{t} \\
& \beta_{t}=\mu+F \beta_{t-1}+\eta_{t}
\end{aligned}
$$

with the assumptions that $\varepsilon_{t} \sim$ i.i.d.N $(0, R), \eta_{t} \sim$ i.i.d.N $(0, Q)$ and $E\left(\varepsilon_{t}, \eta_{t}\right)=0$. To estimate the unobserved state variable $\beta_{t}$ in the linear state space model, we use a Kalman filter. Assuming the parameters $\mu, F, R, Q$ are known, the Kalman filter consists of two steps: prediction and updating. Starting with initial value of $\beta_{0 \mid 0}$ and its covariance $P_{0 \mid 0}$, the Kalman filter iterates through the following equations from $t=1, \ldots, T$,

Prediction:

$$
\begin{aligned}
& \beta_{t \mid t-1}=\mu+F \beta_{t-1 \mid t-1} \\
& P_{t \mid t-1}=F P_{t-1 \mid t-1} F^{\prime}+Q
\end{aligned}
$$




$$
\begin{aligned}
& \eta_{t \mid t-1}=y_{t}-y_{t \mid t-1}=y_{t}-x_{t} \beta_{t \mid t-1} \\
& f_{t \mid t-1}=x_{t} P_{t \mid t-1} x_{t}^{\prime}+R .
\end{aligned}
$$

\section{Updating}

$$
\begin{aligned}
& \beta_{t \mid t}=\beta_{t \mid t-1}+K_{t} \eta_{t \mid t-1} \\
& P_{t \mid t}=P_{t \mid t-1}-K_{t} x_{t} P_{t \mid t-1}
\end{aligned}
$$

Note that, condition on information up to $t-1$, equations (A3) and (A4) are the predicted values of $\beta$ and its covariance while equations (A5) and (A6) are the prediction error and its covariance, respectively. The Kalman gain, $K_{t}=P_{t \mid t-1} x_{t}^{\prime} f_{t \mid t-1}^{-1}$, determines the amount of new information to be updated from the prediction error and $x_{t} P_{t \mid t-1}$, respectively, in equations (A8) and (A9) .

The Kalman filter provides inference for the state vector using information up to time $T$, $\beta_{1 \mid 1}, \ldots, \beta_{T \mid T}$. To obtain a more accurate inference on $\beta$, we use all available information from period 1 to period $T$. This will produce a smooth estimate of $\beta$. To do so, we iterate backward from period $T$ to period 1 using the smoothing equations:

$$
\begin{aligned}
& \beta_{t \mid T}=\beta_{t \mid t}+P_{t \mid t} F^{\prime} P_{t+1 \mid t}^{\prime}\left(\beta_{t+1 \mid T}-F \beta_{t \mid t}-\mu\right) \\
& P_{t \mid T}=P_{t \mid t}+P_{t \mid t} F^{\prime} P_{t+1 \mid t}^{\prime}\left(P_{t+1 \mid T}-P_{t+1 \mid t}\right)\left(P_{t \mid t} F^{\prime} P_{t+1 \mid t}^{\prime}\right)^{\prime} .
\end{aligned}
$$

\section{Table 1. Parameter estimates of time-varying parameter model}

\begin{tabular}{|c|c|c|c|c|}
\hline & Estimate & Std.Error & $t$-stats & $\operatorname{Prob}(>t)$ \\
\hline$\alpha_{0}$ & -0.0069 & 0.0065 & -1.06 & 0.2897 \\
\hline$\alpha_{G}$ & -0.7663 & 0.0331 & -23.13 & 0.0000 \\
\hline$\alpha_{Y}$ & -1.7631 & 0.3896 & -4.53 & 0.0000 \\
\hline$\theta_{\varepsilon}$ & -9.3765 & 0.2049 & -45.76 & 0.0000 \\
\hline$\theta_{\eta}$ & -7.2046 & 0.3808 & -18.92 & 0.0000 \\
\hline
\end{tabular}

Table 2. Parameter estimates of linear regression model

This article is protected by copyright. All rights reserved. 


\begin{tabular}{|c|c|c|c|c|}
\hline & Estimate & Std.Error & $t$-stats & $\operatorname{Prob}(>t)$ \\
\hline$\alpha_{0}$ & -0.0109 & 0.0050 & -2.17 & 0.0323 \\
\hline$\alpha_{G}$ & -0.7661 & 0.0353 & -21.67 & 0.0000 \\
\hline$\alpha_{Y}$ & -1.8757 & 0.5391 & -3.48 & 0.0008 \\
\hline$\rho$ & 0.0259 & 0.0125 & 2.08 & 0.0405 \\
\hline
\end{tabular}

\section{O}

Table 3. Parameter estimates of Lee-Strazicich (2003) unit root test regression

\begin{tabular}{|c|c|c|c|}
\hline (a) & \multicolumn{3}{|c|}{ Debt-GDP ratio } \\
\hline & Estimate & Std.Error & $t$-stats \\
\hline$\tilde{S}_{t-1}$ & -0.2550 & 0.0428 & -5.96 \\
\hline Intercept & 0.0016 & 0.0076 & 0.21 \\
\hline$D_{1 t}$ & 0.0991 & 0.0418 & 2.37 \\
\hline$D T_{1 t}$ & -0.0389 & 0.0121 & -3.22 \\
\hline $\bar{D}_{2 t}$ & 0.0154 & 0.0395 & 0.39 \\
\hline$D T_{2 t}$ & 0.0075 & 0.0121 & 0.62 \\
\hline$\left(\tilde{b}^{)}\right)$ & \multicolumn{3}{|c|}{ Surplus-GDP ratio } \\
\hline$\tilde{S}_{t-1}$ & -0.6728 & 0.0905 & -7.43 \\
\hline Intercept & 0.0066 & 0.0060 & 1.09 \\
\hline$D_{1 t}$ & 0.0881 & 0.0293 & 3.01 \\
\hline$D T_{1 t}$ & -0.0795 & 0.0157 & -5.05 \\
\hline$D_{2 t}$ & -0.0447 & 0.0260 & -1.72 \\
\hline$D T_{2 t}$ & 0.0886 & 0.0159 & 5.57 \\
\hline
\end{tabular}

Figure1.TheU.S.publicdebtandprimarysurplusasaproportionofGDP

Figure2.Time - varyingparameter $\hat{\rho}_{t-1}$ estimates

Figure3.Actualsurplus/GDPandestimatedsurplus/GDPbasedontime - varying parametermodelandthelinearregression.

This article is protected by copyright. All rights reserved. 


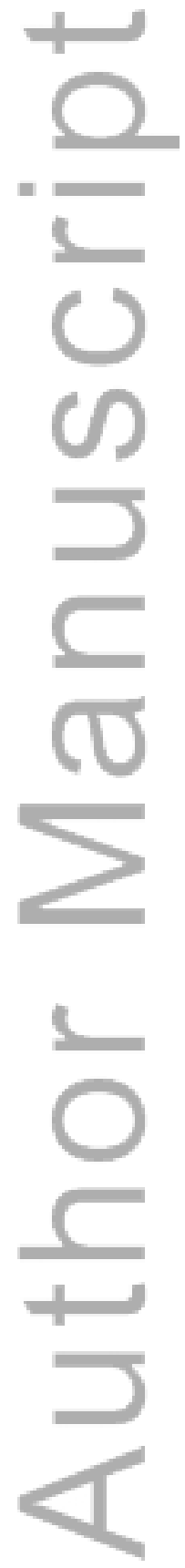

This article is protected by copyright. All rights reserved. 


\section{University Library}

\section{- M M N E R VA A gateway to Melbourne's research publications}

Minerva Access is the Institutional Repository of The University of Melbourne

Author/s:

Thanh, DN;Suardi, S;Chua, CL

Title:

THE BEHAVIOR OF US PUBLIC DEBT AND DEFICITS DURING THE GLOBAL FINANCIAL CRISIS

Date:

2017-01-01

Citation:

Thanh, D. N., Suardi, S. \& Chua, C. L. (2017). THE BEHAVIOR OF US PUBLIC DEBT AND DEFICITS DURING THE GLOBAL FINANCIAL CRISIS. CONTEMPORARY ECONOMIC POLICY, 35 (1), pp.201-215. https://doi.org/10.1111/coep.12166.

Persistent Link:

http://hdl.handle.net/11343/290819 